\title{
DE ADMINISTRADOR A GESTOR DO CONHECIMENTO: A COMUNIDADE DE PRÁTICA DESENVOLVENDO O PROFISSIONAL, A ORGANIZAÇÃO E A COMUNIDADE.
}

\author{
Geraldo Morceli Bolzani Júnior ${ }^{1}$ \\ Marcelo Stein de Lima Sousa ${ }^{2}$ \\ Décio Estevão do Nascimento ${ }^{3}$
}

\begin{abstract}
RESUMO
Nos estudos de desenvolvimento local, o conceito de capital social surgiu como um dos componentes essenciais dos processos de desenvolvimento de comunidades. Ao mesmo tempo, ao se afirmar como diferencial competitivo do século XXI, o conhecimento fez surgir a disciplina gestão do conhecimento que passou a trabalhar a interação social como elementochave na gestão do conhecimento organizacional. O Administrador, ao compreender as interações que acontecem tanto nos processos de desenvolvimento local como, principalmente, nos processos de gestão do conhecimento organizacional, no contexto de uma economia globalizada que expõe as empresas e as comunidades a uma competição cada vez mais acirrada, dominará diferenciais que irão Ihe conferir capacidade de intervenção em ambientes economicamente e socialmente complexos. A competitividade nesses ambientes implica em uma integração da ação entre indivíduos, organizações e comunidades empreendedoras no que diz respeito a sua prática e identidade. O conceito de comunidade de prática (Wenger, 1998) utilizado pelos autores para a compreensão dessas questões é uma ferramenta de gestão do conhecimento que tem um histórico de aplicação de sucesso em grandes corporações como Banco Mundial, IBM e outras. Ao apresentar o conceito de comunidades de prática do ponto de vista organizacional e de interesse do Administrador, esse artigo também busca fazer, exploratoriamente, uma análise das possibilidades da aplicação do conceito como aglutinador das ações individuais, organizacionais e comunitárias dentro da perspectiva de desenvolvimento dos setores público, privado e terceiro setor.
\end{abstract}

Palavras-chave: capital social, comunidades de prática, gestão do conhecimento, gestão organizacional, desenvolvimento da comunidade, terceiro setor.

\begin{abstract}
Modern management implies in knowledge management. It requires expertise in social relationship. The concept of community of practice explains how the process occurs, indicating that is possible cultivate social interations. To managers it is a tool that can generate learning inside the company and can steward processes of development to in local communities.
\end{abstract}

Key-words: social capital, community of practice, knowledge management, corporative mangement, gestão organizacional, community building, non-profits.

\footnotetext{
${ }^{1}$ Mestrando do PPGTE - Programa de Pós-Graduação em Tecnologia do CEFETPR

${ }^{2}$ Doutorando pela UFPR e Professor do PPGTE

${ }^{3}$ Doutor pela Université de Technologie de Compiegnè, França e Professor do PPGTE
} 


\section{INTRODUÇÃO}

Para onde olhar daqui para frente? Muito provavelmente, para as pessoas. Os trabalhadores do conhecimento serão avaliados e valorizados de acordo com sua habilidade de criar, imaginar, julgar e construir relacionamentos.

Revista Exame. Edição Especial de 35은 aniversário. Seção Inovação - Gestão, pg. 74.

A reunião de pessoas, nas mais variadas formas, para realizar uma tarefa ou algum trabalho de interesse de um grupo é tão antiga quanto a humanidade. Podemos afirmar, também, que o problema da realização de tarefas conjuntas sempre esteve presente nas mais diferentes áreas do conhecimento. A psicologia se preocupa com o indivíduo e a dinâmica emocional e afetiva nos grupos; a sociologia em entender a estrutura e o processo de funcionamento de grupos e a sua interação com a sociedade; a economia com as relações de troca e o comportamento de indivíduos dentro de grupos no mercado e assim por diante. Porém, o mundo está evoluindo muito rapidamente, como nos explica Almeida (1998, p. 116-117)

A criação de novas tecnologias, aliada a fatores de ordem política, diversifica e dá nova feição às relações internacionais. Novos mercados consumidores surgem, ao mesmo tempo em que exigem um incremento modificativo na sistemática do comércio entre nações. As técnicas de produção, aprimoradas pelo uso da cibernética e da informática, alcançam um patamar nunca antes experimentado. Verifica-se uma segunda Revolução Industrial. A partir de então, é implementado o instrumental necessário à plena consecução desse processo. Nasce o fenômeno da globalização da economia.

Mas, as conseqüências desse processo não são só econômicas. Há pressões políticas, ambientais, culturais sobre as mais diversas sociedades. Nesse processo de aceleração da modernidade, a tecnologia tem um papel preponderante no processo. O projeto americano de guerra tecnológica chamado Guerra nas Estrelas derrubou o império soviético. A engenharia genética tem trazido, na área de alimentos, soluções e preocupações para produtores e consumidores. A volatilidade do mercado financeiro internacional, cuja origem está também nas facilidades de comunicação, é uma ameaça para economias menos sólidas. As mídias digitais transformam a vida do cidadão 
comum e, nas organizações, a informatização dos processos industrias e administrativos deixou de ser um diferencial competitivo para se tornar uma necessidade. O resultado prático que queremos enfocar aqui é que as organizações, e conseqüentemente, os Administradores estão trabalhando em um ambiente cada vez mais complexo e instável, onde encontrar soluções razoáveis exigirá um esforço em direção ao domínio de tecnologia e de conhecimento. Esse artigo, ao chamar a atenção do Administrador para as transformações que estão ocorrendo no âmbito das empresas e da sociedade, discorre sobre gestão do conhecimento e interações sociais, apontando para comunidades de prática como um conceito que agrega valor para as organizações e que pode contribuir para o desenvolvimento de comunidades locais.

\section{AS ORGANIZAÇÕES}

Drucker (1999) afirma que "a sociedade e a família são, a organização faz". E é adaptando-se continuamente a um ambiente de complexidade e instabilidade que as organizações permanecem fazendo. Observe-se, do ponto de vista da resposta conceitual aos ambientes das décadas de 80 e 90 .

$\mathrm{Na}$ década de 80 , os esforços de gestão estavam direcionados para estabelecer, através do posicionamento estratégico, o tamanho ideal para as organizações. O princípio da reengenharia era criar competitividade para a organização pela concentração das atividades em um core bussines, na atividade principal da organização.

$\mathrm{Na}$ década de 90, a atenção voltou-se para os processos produtivos: os programas de melhoria da qualidade ocuparam lugar de destaque. $O$ conceitochave foi o de qualidade total. A preocupação não era mais com estratégia de negócios, mas com a qualidade de processo. Só assim seria possível competir no mercado com produtos melhores e mais baratos gerados por processo gerencialmente eficazes e economicamente eficientes.

Porém, com o surgimento da internet, das novas mídias digitais, da disseminação do computador, surge o embrião de uma economia sustentada por novas forças. São as possibilidades da tecnologia digital que permitem o surgimento de novos produtos, de novas profissões e de novos mercados. Este 
novo ambiente econômico está fundamentado em dois pilares: nas tecnologias digitais e no conhecimento. Isso gera mais uma mudança no ambiente de atuação das empresas. O que, por sua vez, força uma mudança no foco das estratégias das organizações. Ou seja, estamos numa época que será competitivo quem detiver tecnologia e conhecimento e souber geri-los. Assim como foi competitivo quem uma determinada época soube dominar a reengenharia e a qualidade total.

\section{CONHECIMENTO: NOVO FATOR DE COMPETITIVIDADE}

Vários autores em várias áreas colocam o conhecimento como foco de suas teses. $\mathrm{O}$ assunto deixou de ser uma questão de interesse educacional e tornou-se uma questão que permeia toda a discussão de futuro da sociedade passando também para o domínio de áreas como política, sociologia, economia, entre outras, atingindo também a ciência da administração.

Numa visão política, Demo (2000) afirma que o conhecimento é peça fundamental para o desenvolvimento social e econômico do País. Afirma que o futuro do combate a pobreza no Brasil deve passar por uma "política social do conhecimento", fazendo pesadas críticas a ação assistencialista do Estado. Faz uma distinção entre educação e conhecimento e diz: "Nem sempre é fácil combinar os dois termos, mas parece cada vez mais claro que as oportunidades de desenvolvimento dependem crucialmente da qualidade educativa popular e do manejo crítico e criativo do conhecimento".

Também com uma visão mais abrangente das questões brasileiras, Moura Castro (2000) fala de educação no Brasil e diz que é impossível repetir o fenômeno mais espantoso do milagre econômico da década de setenta: crescimento sem educação.

Em economia, Ernst e Lundvall (1997) citam a pesquisa em países da OECD que mostra que a capacidade de aprender determina o sucesso econômico, não apenas para empresas mas também para regiões e países. 0 que fez surgir o conceito de learning economy, baseado principalmente na proposição do aprendizado econômico como um processo interativo, preponderantemente social. 
Mas é Peter Drucker, no campo da Administração de Empresas, que fala do surgimento de um novo profissional, o trabalhador do conhecimento. Segundo Drucker (2001), "para ser eficaz, o conhecimento deve ser especializado, o que implica dizer que os trabalhadores do conhecimento precisam ter acesso a uma organização - isto é, uma entidade coletiva capaz de congregar ampla diversidade de trabalhadores do conhecimento, e aplicar suas especialidades na obtenção de um produto final comum". O trabalhador do conhecimento, portanto, atuará em uma organização. Porque são elas, as organizações, as mais interessadas no uso do conhecimento como um fator estratégico que irá dar conta das grandes transformações no ambiente no qual as organizações estão inseridas.

O cenário está montado: a organização, foco da ação, debatendo-se com a complexidade e utilizando o conhecimento e a tecnologia como soluções. Portanto, há várias questões a serem resolvida pela organização: $O$ que é exatamente o conhecimento? Onde e como é criado? Como dominar o processo de criação do conhecimento? Como utilizá-lo como um diferencial competitivo? Qual o papel das tecnologias? As respostas tradicionais: focar nos processos de instrução, no treinamento, no desempenho individual isolado. Mas, são freqüentes as reclamações sobre o baixo retorno dos investimentos em treinamento.

\section{GESTÃO DO CONHECIMENTO}

Por isso, a crescente necessidade das organizações privadas de focar explicitamente no conhecimento, assumindo-o como um diferencial competitivo fez surgir a disciplina gestão do conhecimento. Por conseqüência, surge um amplo aparato conceitual sobre conhecimento aplicado às organizações: gestão do conhecimento e estratégia empresarial, gestão do conhecimento e medidas de performance e gestão do conhecimento e tecnologias da informação (Liebowitz, 1999). Mas ainda há grandes desafios. Mesmo porque as respostas fornecidas ainda não estão funcionando adequadamente como nos indica Wenger: "...esforços iniciais focaram em sistemas de informação com resultados desapontadores" (Wenger, 2001, p. 3). McDermott (2000) aponta que a grande armadilha em gestão do conhecimento é usar ferramentas 
e conceitos de gestão da informação para criar sistemas de gestão do conhecimento. A confusão entre conhecimento e informação explica o fracasso da velha abordagem: "conhecimento é diferente de informação e compartilha-lo requer um conjunto de conceitos e ferramentas. Seis características do conhecimento o distinguem de informação: 1. Conhecimento é um ato humano, 2. Conhecimento é o resíduo do pensamento, 3. Conhecimento é criado no presente momento, 4. Conhecimento pertence a comunidade, 5. Conhecimento circula entre comunidades de diversas maneiras e 6 . O novo conhecimento é criado nas fronteiras do velho" (McDermott, 2000, p. 23).

É no contexto do fracasso parcial das novas tecnologias digitais que a interação social surgiu como elemento-chave na gestão do conhecimento organizacional (Lesser \& Prusak, 1999).

\section{RELACIONAMENTOS: CAPITAL SOCIAL}

Nos estudos de desenvolvimento local, o conceito de capital social (Putnam, 1995) surgiu como um dos componentes essenciais dos processos de desenvolvimento. Assim como existe capital financeiro, capital humano e capital tecnológico, existe o capital social que é um recurso que ajuda a sustentar a comunidade. Putnam ${ }^{1}$ (citado por Preece, 2002, p. 37), "afirma que - capital social encoraja a colaboração entre membros do grupos para benefício mútuo". Conseqüentemente, a vida em comunidades com mais capital social é mais fácil que em comunidades com menos capital social.

Prusak \& Cohen definem o capital social, do ponto de vista organizacional, como sendo as relações que fazem uma organização trabalhar de maneira eficiente. No entanto, alertam para o fato de que o aumento da volatilidade, a sobrevalorização da virtualidade e o desconhecimento de como investir no capital social colocam em risco a aparente tranqüilidade de se implementar este capital nas empresas (Prusak \& Cohen, 2001). Para combater o que chamam de inimigos do capital social - a volatilidade do

\footnotetext{
${ }^{1}$ Robert D. Putnam é Professor de Relações Internationais em Dillon e Diretor do Centro de Relações Internacionais na Universidade de Harvard. No seu livro sobre política italiana "Making Democracy Work (Princeton University Press, 1993), Putnam constrói uma fundamentação intelectual consistente para a tese de que o vigor da vida cívica é uma das bases fundamentais para a boa performance de um governo democrático.
} 
ambiente organizacional e a virtualidade cada vez maior do trabalho -, estes autores sugerem algumas medidas para impedir sua erosão:

\section{Concretizar conexões}

- comprometer-se com a fixação - trabalhar para que as pessoas permaneçam na organização. Como destaque em termos de construção de relações, apontam para a necessidade de um trabalho que faça sentido para as pessoas, incluindo a possibilidade de se manter num projeto enquanto fizer sentido.

- realizar promoções internas - garantir a promoção de pessoas a partir de seu pertencimento a redes e comunidades onde se desenvolve a confiança em sua competência e onde o conhecimento e compartilhado.

- garantir tempo e espaço para as pessoas se ligarem pessoalmente - o capital social cresce quando as pessoas trabalham juntas e presencialmente, o que sugere permitir e incentivar a aproximação de pessoas que não estão nos escritórios.

- facilitar as conversações pessoais - promover a troca de conhecimentos através de cafés, chats, bibliotecas, cozinhas, cafezinhos e outros espaços sociais.

- promover redes duradouras - as pessoas se aproximam das outras em função de algum interesse em um domínio particular de trabalho. Elas se envolvem para compartilhar o que sabem, ajudar outros a executar uma tarefa, e gostam da sensação de pertencer a um grupo

\section{Permitir confiança}

- não permitir que as pessoas deixem de confiar - quando existe transparência e as pessoas acreditam na força da lei, vivendo pelas regras de convivência, ocorre um investimento em capital social.

- mostrar confiança-confiando na julgamento das pessoas e concretizando a distribuição da tomada de decisões.

- valorizar comportamentos e resultados - difundir sinais claros de valorização daquilo que se espera seja a forma de se trabalhar na organização.

- premiar a confiança - a promoção para posições de liderança de certas 
pessoas indica quais são os valores, as abordagens e as maneiras valorizadas na organização.

\section{Promover a cooperação}

- fornecer um senso comum de propósito - e uma boa estratégia para aglutinar as pessoas em torno de um trabalho que faça sentido.

- premiar a cooperação - uma maneira de fazer com que as pessoas se envolvam cada vez mais e permitir o acesso a participação financeira nos resultados.

- estabelecer algumas regras - definir regras para a cooperação auxilia a criar o habito de cooperar nas pessoas.

- contratar pensando no capital social - uma política de recursos humanos que leve em conta questões de relacionamento, confiança e cooperação auxilia a promover o capital social.

Para Nahapiet \& Goshal (1998), o capital social pode ser visto como a "soma dos recursos reais e potenciais embutidos nas, disponíveis através de, e derivados da rede de relacionamentos possuídos por um indivíduo ou unidade social". Definem ainda que o capital social possui três dimensões associadas:

- a estrutural, que se refere a formação de redes informais que permitam ao indivíduo reconhecer outras pessoas com recursos potenciais que não estão disponíveis para ele;

- a relacional, que sugere que o capital social se desenvolve quando o indivíduo acredita que suas ações geram contribuições valorizadas pela comunidade e que estão dentro dos padrões de competência estipulados; e

- a cognitiva, que indica a necessidade de contexto e linguagens comuns para criar as conexões que promovem o capital social.

\section{CULTIVANDO COMUNIDADES DE PRÁTICA}

Em qualquer organização existe uma estrutura formal descrita por organogramas, documentos e procedimentos, e um ambiente informal baseado 
em relacionamentos e auto-organização de grupos de pessoas. Por trás do aspecto formal da organização encontra-se uma rede informal de pessoas que trabalham juntas compartilhando conhecimento, solucionando problemas e trocando idéias, estórias e confidências. Quando devidamente apoiadas pelo lado formal da organização, estas "comunidades de prática" formam componentes críticos para construção, compartilhamento e aplicação do conhecimento organizacional (Lesser \& Prusak, 1999).

- auxiliando a impulsionar estratégias, por exemplo, transformando-se na principal catalisadora de uma estratégia de gestão do conhecimento, em função deste ser um assunto fundamental para a sua existência;

- iniciando novos negócios, por exemplo, a partir de interesses comuns, funcionários podem gerar uma nova unidade de negócios dentro de uma empresa;

- resolvendo rapidamente problemas, por saber a quem perguntar, como perguntar, e em quais questões e importante focar para solucionar o problema;

- transferindo as melhores práticas, pois e o meio ideal para compartilhar e difundir práticas dentro da organização;

- desenvolvendo habilidades profissionais, pois elas funcionam como ambiente de aprendizado para os novatos, com os outros membros atuando como mentores e treinadores;

- auxiliando a recrutar e reter talentos, adequando e customizando projetos que sejam interessantes a todos os membros da comunidade.

Mas que são comunidades de prática? Para Etienne Wenger idealizador do conceito - elas são grupos de pessoas reunidas informalmente ligadas pela expertise e paixão compartilhadas por um empreendimento conjunto: engenheiros envolvidos na perfuração de poços, consultores que se especializaram em marketing estratégico, ou advogados defendendo um cliente em uma causa complicada. Algumas delas se reúnem regularmente, outras estão conectadas basicamente através de correio eletrônico, e podem ou não ter agendas explícitas. Todas elas, no entanto, compartilham sua experiência e 
conhecimento de maneira criativa para promover novas abordagens para problemas que a comunidade identificou (Wenger, 2000). As comunidades de prática diferem de outros arranjos organizacionais de várias maneiras (veja Tabela 1).

Tabela 1 - Comunidades de prática e outras estruturas organizacionais

\begin{tabular}{|c|c|c|c|c|}
\hline & Qual o propósito? & Quem pertence? & $\begin{array}{l}\text { O quê os mantém } \\
\text { juntos? }\end{array}$ & Quanto dura? \\
\hline $\begin{array}{l}\text { Grupos formais } \\
\text { de trabalho }\end{array}$ & $\begin{array}{l}\text { Entregar um produto } \\
\text { ou serviço }\end{array}$ & $\begin{array}{l}\text { Membros incluem } \\
\text { qualquer um que se } \\
\text { reporte ao gerente } \\
\text { do grupo }\end{array}$ & $\begin{array}{l}\text { Requisitos do } \\
\text { trabalho e objetivos } \\
\text { comuns }\end{array}$ & $\begin{array}{l}\text { Até a próxima } \\
\text { reorganização }\end{array}$ \\
\hline $\begin{array}{l}\text { Equipes de } \\
\text { Projeto }\end{array}$ & $\begin{array}{l}\text { Completar uma } \\
\text { tarefa especíca }\end{array}$ & $\begin{array}{l}\text { Membros são } \\
\text { designados } \\
\text { pela gerência }\end{array}$ & $\begin{array}{l}\text { As metas e } \\
\text { milestones do projeto }\end{array}$ & $\begin{array}{l}\text { Até que o projeto } \\
\text { termine }\end{array}$ \\
\hline
\end{tabular}

Para Wenger, a prática e, antes de mais nada, "um processo pelo qual podemos experimentar o mundo e nosso envolvimento nele como algo que faça sentido" (Wenger, 1998). Para tanto, as pessoas precisam negociar 0 significado daquilo que fazem cotidianamente. Esta negociação de significado esta vinculada a interação de dois processos - participação e reificação (coisificação) - que formam uma dualidade fundamental para a experiência humana de significado e para a natureza da prática.

Dentro deste contexto, uma comunidade de prática pode ser descrita a partir de três dimensões através das quais a prática serve como fonte de coerência de uma comunidade: empreendimento comum, envolvimento mútuo, e repertório compartilhado. Uma prática não existe em abstrato, ela depende de pessoas envolvidas em ações cujo significado e negociado entre as pessoas - ela só existe porque estas pessoas pertencem a uma comunidade engajada em concretizar um empreendimento. 0 empreendimento comum é negociado entre os membros da comunidade a partir de um processo social de negociação que reflete 0 envolvimento das pessoas na comunidade. 0 
repertório compartilhado é criado pela comunidade aos poucos. A busca conjunta de concretização do empreendimento cria recursos para a negociação de significado. Os elementos do repertório podem ser muito heterogêneos e obtém sua coerência não como símbolos, atividades ou artefatos específicos, mas sim do fato que eles pertencem à prática de uma comunidade em busca de um empreendimento (Wenger, 1998).

Figura 1 - Três dimensões das comunidades de prática

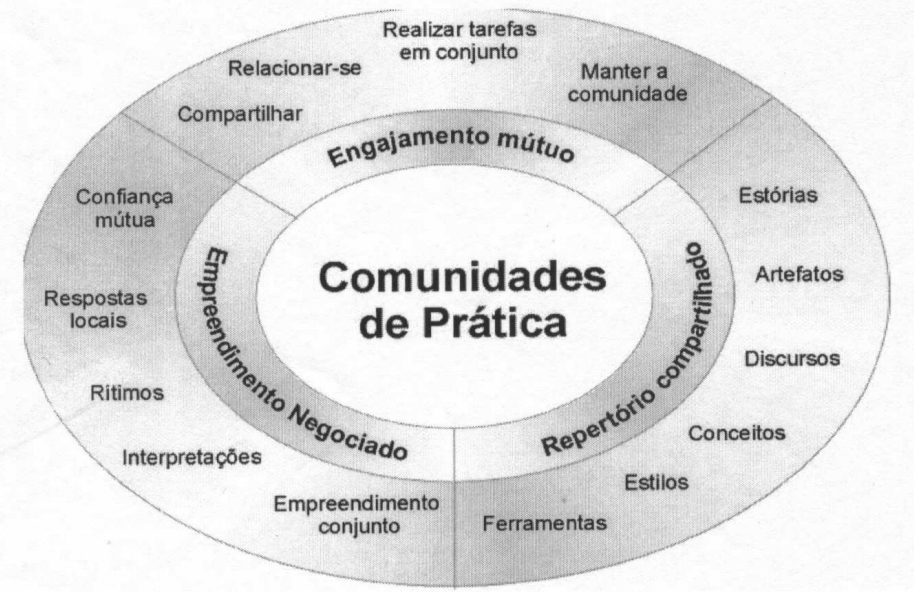

Estes três domínios, em conjunto com aqueles sugeridos por Prusak \& Cohen - o estabelecimento de relações entre as pessoas, a necessidade de estabelecer laços de confiança entre elas, e a promoção da cooperação -, podem ser projetadas nos três domínios característicos de uma comunidade de prática: o envolvimento entre as pessoas, o compartilhamento de um repertório e o empreendimento comum a ser alcançado.

Pensando na disponibilização de tecnologias de informação para dar suporte a comunidades de prática, Wenger sugere treze elementos fundamentais de uma comunidade bem sucedida que as tecnologias da informação e comunicação podem afetar (Wenger, 2001). Mesmo não havendo interesse específico em tecnologias da informação, esses elementos são indicações claras de funcionamento de uma comunidade, sob os quais podemos exercer influência. 


\section{Tempo \& Espaço}

- Presença \& Visibilidade. Uma comunidade precisa estar presente na vida de seus membros e ser visível para eles

- Ritmo. Uma comunidade tem seu ritmo de eventos e rituais que reafirmam suas ligações e valores

\section{Participação}

- Variedade de interações. Os membros de uma comunidade de prática precisam interagir para construir sua prática compartilhada

- Eficiência de envolvimento. As comunidades de prática competem com outras prioridades na vida de seus membros; a participação deve ser fácil

\section{Criação de valores}

- Valores de curto-prazo. As comunidades de prática desenvolvem-se a partir do valor que fornecem aos seus membros e ao contexto organizacional deles; cada interação precisa criar algum valor

- Valores de longo-prazo. Como os membros se identificam com o domínio da comunidade, existe um compromisso de longo prazo com seu desenvolvimento

\section{Conexões}

- Conexões com o mundo. Uma comunidade de prática pode criar valores permitindo a conexão com uma área mais ampla ou outra comunidade com a qual seus membros querem se manter a par

\section{Identidade}

- Identidade pessoal. Pertencer a uma comunidade de prática é parte da identidade de quem é competente

- Identidade comunal. Comunidades bem sucedidas possuem uma identidade bem marcada que seus membros herdam em suas próprias vidas 


\section{Pertencimento}

- Pertencimento \& Fronteiras. 0 valor do pertencimento não é apenas instrumental, mas também pessoal: interagindo com colegas, desenvolvendo amizades, construindo confiança

- Fronteiras complexas. Comunidades de prática possuem múltiplos níveis e tipos de participação. É importante para pessoas na periferia da comunidade serem capazes de participar de alguma forma. E, também dentro das comunidades, as pessoas formam sub-comunidades em torno de áreas de interesse.

\section{Desenvolvimento da comunidade}

- Evolução: maturação e integração As comunidades de prática evoluem conforme avançam através de estágios de desenvolvimento e estabelecem conexões com o/no mundo

- Construção ativa da comunidade. Comunidades de prática bem sucedidas geralmente possuem uma pessoa ou grupo nuclear que assumem a responsabilidade por fazer a comunidade andar.

Alguns autores da área econômica compartilham da idéia de que a ação econômica está embutida em sistemas concretos e dinâmicos de relações sociais (Granovetter, 1985). 0 fato de que os membros de uma comunidade de prática tendem a estar extensivamente conectados significa que, de várias maneiras e em vários graus, eles estão embutidos em diversos conjuntos de relações sociais. Este multipertencimento permite que as pessoas estejam dotadas de capital social. Assim, o conceito de embeddness pode ser visto como a relação das pessoas com outras em uma coletividade, o que afeta seu comportamento e pode trazer conseqüências para a sua ação (Oinas, 1999).

\section{LIDANDO COM A COMPLEXIDADE: COMPETÊNCIAS PROFISSIONAIS, COMPETITIVIDADE ORGANIZACIONAL E DESENVOLVIMENTO LOCAL}

O Administrador ao assumir o papel de gestor do conhecimento e empregando o conceito de comunidade de prática compreenderá as interações que acontecem nos processos de aprendizado social e, consequentemente, 
dominará diferenciais que irão the conferir capacidade de intervenção em ambientes organizacionais complexos. Está pode ser considerada uma capacidade técnica cuja eficácia pode ser atribuída ao indivíduo. Mas não pode ser confundida com habilidades gerenciais do tipo domínio de ferramentas nem do tipo motivacionais. O sucesso do processo dentro da organização depende do desempenho do grupo, da comunidade que se cria em torno de uma prática. Portanto, mais do que ferramenta e mais do que motivação, o sucesso depende do significado que esta prática tem na vida das pessoas envolvidas.

Mas se, fundamentalmente, o que move as comunidades de prática é o aprendizado construido socialmente. Isso significa que este mesmo processo de aprendizado também é capaz de se tornar um diferencial nos processos de desenvolvimento local. Assim como pode existir comunidades de prática dentro de organizações, e além delas, também pode existir comunidades de prática envolvidas com o desenvolvimento local. A análise exploratória que fazemos das possibilidades da aplicação do conceito de comunidade de prática como aglutinador das ações individuais, organizacionais e comunitárias necessariamente passa pela perspectiva de envolvimento dos setores público, privado e terceiro setor.

A economia globalizada expõe empresas e comunidades a uma competição cada vez mais acirrada e não há dúvida que o sucesso da sociedade brasileira depende da qualidade das lideranças cívicas, empresariais e governamentais. Porém, o sucesso dos empreendimentos privados ou públicos estará no domínio da prática desenvolvida, na possibilidade de aprendizado entre envolvidos e na confiança entre parceiros.

A pequena comunidade é 0 elemento estratégico para 0 desenvolvimento local. Assim como acontece na organização, é no âmbito de ação da comunidade que ocorrem os processos de interação social. E é essa interação social que tem o poder de construir, através da prática e da identidade compartilhadas pelos seus membros, soluções inovadoras para a sociedade como um todo. 
Revista Eletrônica de Ciência Administrativa (RECADM) - ISSN 1677-7387

Faculdade Cenecista de Campo Largo - Coordenação do Curso de Administração

v. 1, n. 1, maio/2003 - http://revistas.facecla.com.br/index.php/recadm/

\section{Referências}

ALMEIDA, A. Fo . Globalização e identidade cultural. São Paulo: Editorial Cone Sul, 1998.

CASTRO, C. de M. "A educação é o combustível do crescimento no Brasil". Revista Veja, São Paulo, 27.dezembro.2000.

DEMO, P. Política social do conhecimento. Petrópolis: Editora Vozes, 2000.

DRUCKER, P. Sociedade pós-capitalista. São Paulo: Editora Pioneira, 1999.

"A nova força de trabalho". Valor Econômico, São Paulo, 6.novembro.2001.

Suplemento The Economist.

ERNST, D.; LUNDVALL, B. Information technology in the learning economy challenges for developing countries. Druid Working Paper, Dinamarca, v. 97, n.12, 1997.

GRANOVETTER, M. "Economic action and social structure: The problem of embedeedness". American Journal of Sociology, v. 91, 1985. p. 481-510

LESSER, E.; PRUSAK, L. "Communities of practice, social capital and organizational knowledge". White paper, IBM Institute for Knowledge Management, Cambridge, 1999.

LIEBOWITZ, J. et al. Knowledge management - handbook. New York: CRC Press, 1999.

McDERMOTT, R. Why information technology inspired but cannot deliver knowledge management. In: Lesser, E. et al. Knowledge and communities. Woburn: ButterworthHeinemann, 2000. p. 23.

NAHAPIET, J.; GHOSHAL, S. "Social capital, intellectual capital and the organizational advantage". Academy of Management Review, v. 23, n. 2, abril, 1998. p. 242-266.

OINAS, P. "Voices and silences: The problem of access to embeddedness". Geoforum, v. 30, 1999. p. 351-361.

PREECE, J. "Suporting community and building social capital". Communications of the ACM, v.45, n. 4, p. 37, 2002.

PRUSAK, L.; COHEN, D. "How to invest in social capital ". Harvard Business Review, v. 79 , n. 6 , junho, 2001. p. 86-93.

PUTNAM, R. Bowling alone: America's declining social capital. Journal of Democracy., Baltimore, v. 6, n. 1, p. 65-78, 1995. Disponível em:

http://muse.jhu.edu/demo/journal of democracy/v006/putnam.html\#REF11

WENGER, E. Communities of practice: learning, meaning and identity. Nova lorque: Cambridge University Press, 1998.

. Supporting communitites of practice: a survey of community-oriented technologies. Relatório de pesquisa, versão 1.3, 2001. Disponível em: www.ewenger.com.

WENGER, E.; SNYDER, A. W. Jr. "Communities of practice: The organizational frontier”. Harvard Business Review, v. 75, n.1, dezembro/janeiro, 2000. 